\title{
Radiation damage research at LAMFI: Laboratory of Materials and lon Beams
}

Pesquisa em dano por irradiação em materiais no LAMFI: Laboratório de Materiais e Feixes lônicos

Matheus A Tunes ${ }^{1}$, Francisco T. Degasperi², Claudio L Rodrigues ${ }^{3}$, Thiago F. Silva ${ }^{3}$, Manfredo H. Tabacniks ${ }^{3}$, Nemitala Added ${ }^{3}$, Cláudio G Schön ${ }^{1}$

\section{ABSTRACT}

Nuclear energy represents $13 \%$ of the present worldwide electric power consumption, but in Brazil only about $2.4 \%$ of the energy matrix is due to the nucleo-electric power. As the Brazilian hydroelectric capabilities have been threatened by the water supply shortage by environmental conditions, nuclear technology need to overcome specific challenges aiming at supporting the nuclear reactors development in a sustainable, reliable and efficient perspective. This work addresses the recent theoretical and experimental activities carried out at IFUSP, FATECSP+CEETEPS and POLI-USP in the field of materials sciences and the current challenges of using ion beams to emulate neutron damage in cladding materials candidates with enhanced properties towards accident conditions. Additionally, a new vacuum system is introduced coupled to the LIO-LAMFI (LAMFI is an acronymous to the portuguese expression "Laboratório de Materiais e Feixes lônicos".) implanter allowing to extend the capability of the system to perform implantation at temperatures higher than room temperature.

Keywords: Nuclear Materials; Implanter; Ion Beams; Irradiation Damage; Rutherford Backscattering; Vacuum Technology; SRIM.

\section{RESUMO}

A energia nuclear representa cerca de $13 \%$ do consumo mundial de eletricidade, mas no Brasil esse percentual é de apenas 2.4\%. Uma vez que as capacidades hidroelétricas do Brasil estão sendo constantemente ameaçadas por condições ambientais e meteorológicas, a tecnologia nuclear nacional necessita superar alguns desafios visando dar suporte ao desenvolvimento de novos reatores nucleares sustentáveis, seguros e mais eficientes. Este trabalho visa descrever as recentes atividades experimentais e teóricas desenvolvidas no IFUSP, na FATECSP+CEETEPS e na Escola Politécnica da USP no campo de ciências dos materiais utilizando feixes iônicos para simular o dano por irradiação neutrônica em materiais estruturais candidatos aos futuros reatores nucleares brasileiros. Adicionalmente, introduzimos o projeto de um novo sistema de vácuo para o implantador LIOLAMFI (Laboratório de Materiais e Feixes lônicos) que irá extender as capacidades experimentais do implantandor, permitindo medidas experimentais em altas temperaturas.

Palavras-chaves: Materiais nucleares; Implantador; Feixes lônicos; Dano por irradiação; Rutherford Backscattering; Tecnologia do Vácuo; SRIM.

\footnotetext{
1 Universidade de São Paulo - Escola Politécnica - Departamento de Engenharia de Materiais e Metalurgia - São Paulo (SP) - Brazil ${ }^{2}$ Faculdade de Tecnologia de São Paulo - São Paulo (SP) - Brazil

${ }^{3}$ Universidade de São Paulo - Instituto de Física - Departamento de Física Experimental - São Paulo (SP) - Brazil

Corresponding author: Matheus A Tunes - Universidade de São Paulo - Escola Politécnica - Departamento de Engenharia de Materiais e Metalurgia - Av. Prof. Mello Moraes, 2463, CEP 05508-030 São Paulo (SP)- Brazil-Email: m.a.tunes@physics.org

Received: 10/23/2016 Accepted: 01/11/2017
} 


\section{INTRODUCTION}

The progress of nuclear technology under the aspects of safety, efficiency, radioactive waste generation and nuclear fuel cycle is strongly related with the understanding in materials science and engineering, in particular on how the neutron irradiation changes the structural components in harsh environments.

In a third generation liquid metal fast breeder reactor (LMFBR) the internal and core components can sustain its structural integrity up to $200 \mathrm{dpa}$ - displacement-per-atom or dpa is a unit to estimate in average how many lattice atoms are displaced from its crystalline position per event of collision of damage around the temperature of $673 \mathrm{~K}$. For generation IV designs like the travelling wave reactor (TWR) - the damage threshold is enhanced up to $600 \mathrm{dpa}$. At high doses like as 200 and $600 \mathrm{dpa}$, the formation and growing of Frank-Reed loops, black dots, bubblesprecipitates and dislocation networks may change the phases, compositions and the microstructure of an alloy leading it to the embrittlement or even to the point of fracture. For light water reactors (LWR) the neutron flux is about $1 \times 10^{13} \mathrm{n} \cdot \mathrm{cm}^{-2} \cdot \mathrm{s}^{-1}$ and the irradiation effects may occur preferentially around 10-50 dpa, although void swelling and irradiation-induced precipitation has paramount importance only in higher dose levels (100 dpa $)^{(1-3,6)}$.

Due to the high doses in a material test reactor (MTR), the sample should be irradiated in hot-cells to satisfy radiation protection regulations. After irradiation, the samples are mechanically tested following security protocols in order to protect structures, and hence to reduce the occupational dose for workers against dangerous effects of radiation. In this way the use of a MTR is expensive (order of magnitude of million dollars for a single test), and they are also limited in terms of sample geometry, requiring long-time tests to complete a single irradiation run to reach 10-100 dpa (up to three years). Only a few countries are currently operating MTRs such as: Belgium, United States, Russia and Norway. The worldwide nuclear policy is quite restricted, the possibility of agreements to use foreign MTRs is limited which may compromise the scientific and technological development in Brazil.

A promising solution to the absence of a MTR consists of using particle accelerators and ion implanters to emulate neutron irradiation in nuclear materials. This kind of studies dating back to the golden age of materials sciences and nuclear and atomic physics in fifties and sixties and was initiated in the Cavendish Laboratories in Cambridge and parallel in many universities and laboratories in US as well ${ }^{(4,5)}$.

Many advantages can be pointed out when using ion beams to produce damage in materials. Ions, at the energies often used, do not induce nuclear transmutation and the samples do not become radioactive sources excluding the needed of use a hot-cell. The ion flux can be higher than in nuclear reactors by several orders of magnitude and hence it is faster to reach high dose levels in accelerators which are flexible to the geometry of samples: some authors have reported that $200 \mathrm{dpa}$ in a $50 \mathrm{~nm}$ of Fe target takes only 2 hours of irradiation using $100 \mathrm{keV}$ of $\mathrm{Ar}^{+2}$ beam $^{(4)}$. Although it is impossible to assess the thermo-hydraulic and neutron behaviors of a whole nuclear fuel rod system using ion beams, it is reasonable to use it in order to get more information about mechanical properties of prospective cladding materials in same conditions of nuclear reactors.

This work addresses to the viability of applying a $70 \mathrm{kV}$ implanter situated at the Laboratory of Materials and Ions Beam (LAMFI) located at University of São Paulo - Brazil, to study candidate cladding materials with accident tolerance. A theoretical modelling is presented on dose calculations of implanted argon ions at nanosurface levels in aluminum foils which are compared with Rutherford Backscattering depth profile measurements and SRIM simulations ${ }^{(7-10)}$. Additionally, a new vacuum system coupled to a sample holder with heating is proposed which will allow ion implantation at higher temperatures in order to understand the damage evolution and the role of temperature in the dynamics of defects in such materials.

\section{THEORETICAL CALCULATIONS ON DAMAGE PROFILES}

Some theories have been addressed to the phenomenon of particle irradiation in solids and it is thoroughly discussed in the literature ${ }^{(11,12)}$. They are focused in ab initio predictions of microstructural changes and their effects in the materials behaviour such as swelling, creep, embrittlement and irradiation assisted stress corrosion cracking. The phenomenon itself is subjected to be sensitive to a wide variety of particles (neutrons, ions, and electrons), irradiation energy and spectrum, temperature and stress conditions with the microstructural induced defects playing a major rule. The time-frame of such interactions between irradiated particles and materials is diverse: $10^{-13} \mathrm{~s}$ for displacement of atoms in the crystalline lattice, $10^{-10} \mathrm{~s}$ for the kinetics and around $10^{-6} \mathrm{~s}$ for the recombination of defects by diffusion ${ }^{(21,22)}$.

Regarding Monte Carlo methods, the dpa rate is a function of the flux in a point times the effective displacement cross-section integrated over the energy spectrum. In the Eq. 1 the sum over the index describes the primary ions in the energy spectrum (or particles) and is the atomic number density (particles. $\mathrm{cm}^{-3}$ ) of the target. Unfortunately, the MC methods (and the entire theory of irradiation defects) are far away from a "real" atomistic modelling, but they provide good estimation of the damage profiles ${ }^{(11)}$.

$$
\frac{d}{d t} \operatorname{dpa}(\vec{r})=n \cdot \sum_{i} \int_{E_{i}} \Phi\left(\mathrm{E}_{i}, \vec{r}\right) \cdot \sigma_{D}^{i}\left(E_{i}\right) d E_{i}
$$

The dpa is then calculated through stochastic trajectories from the $\mathrm{MC}$ algorithm considering the production of primary knock-on atoms (PKAs): the atoms displaced from its lattices 
positions though the kinetic energy ( $\mathrm{T}$ ) transfers from the ions. Generally, a PKA ends in an interstitial position and a vacancy is generated. The PKA assumption has particular importance to define the effective displacement cross-section:

$$
\sigma_{D}(E)=\int_{E_{d}}^{T_{\max }(E)} \sigma_{P K A}(T, E) v(T) d T
$$

In the Eq. 2 is the secondary displacement function from the Kinchin-Pease (K-P) model which accounts analytically the Frenkel-Pairs production and the being the primary knock-on cross-section. Some commercial codes are capable to calculate dpa using the assumptions from Eq. 1 and Eq. 2. Using displacement kerma factors available in softwares like HEATR within the NJOY package and MC codes such as MCNP, SERPENT and KENO may provide detailed information of the damage profiles in 3D advanced geometries. These methods, however, have some limitations: (i) reduced capability to transport different types of ions, (ii) the kerma factor does not depend on the displacement energy $\left(E_{d}\right)$ which represents the energy needed to displace an atom from its original position and (iii) due to the complexity of its algorithms, sometimes the simulation has to be performed over a long time to get best accuracy.

The TRIM Monte Carlo code within the SRIM package is a computational routine that allows simulation of depth and damage profiles by means of estimating vacancy-interstitial Frankel-Pairs generation using a method of binary collisions within a hard sphere model. Now with the Kinchin-Pease model, the secondary displacement function has a new formulation:

$$
v_{K P}(T)= \begin{cases}0, & \text { if } T \leqslant E_{d} \\ 1, & \text { if } E_{d} \leqslant T \leqslant 2 E_{d} \\ T / 2 E_{d}, & \text { if } 2 E_{d} \leq T \leqslant E_{c} \\ E_{c} / 2 E_{d}, & \text { if } T \geq E_{c}\end{cases}
$$

In Eq. $3 \mathrm{E}_{\mathrm{c}}$ is the superior cut-off energy for the elastic and inelastic interactions. Early in seventies Norgett, Robinson and Torrens (NRT) developed a new approach to the secondary displacement function which takes in account an efficiency factor $(\kappa=0.8)$ from the anisotropy and a function called $\mathrm{E}_{\mathrm{D}}(\mathrm{T})$ which is the energy available to induce displacements. The SDF in the NRT model is:

$$
v_{N R T}=\kappa \frac{E_{D}(T)}{2 E_{d}}
$$

This approach has been accepted by the nuclear materials community all over the world. The function $\mathrm{E}_{\mathrm{D}}(\mathrm{T})$ can be calculated from the total electronic energy loss in a cascade event subtracted by the PKA energy. SRIM is capable to calculate the number of vacancies generated per ion per Angstrom and then the dpa rate from a given ion fluence (particles. $\mathrm{cm}^{-2}$ ) can be estimated. For the interested reader, we suggest the paper written by M.I. Bratchenko et. al. ${ }^{(1)}$ in which the current dpa calculation, theory and simulations are described in deeper details.

\section{A proper procedure to estimate the damage rate using SRIM}

Here the correct procedure to estimate the dpa rate using SRIM Monte Carlo code is de-scribed. This "recipe" is from the R.E. Stoller most recent work ${ }^{(12)}$. In the SRIM guided user interface it is possible to choose between full and quick cascade damage profile: unfortunately, due to the models, the full cascade simulation mode produces overestimated vacancy concentration. Then, the recipe follows:

a. Choose the quick Kinchin-Pease quick-damage option;

b. The displacement energy has to be selected from the ASTM E521 $1^{(13)}$ which covers a wide variety of materials (40 eV for most metals);

c. Always set the binding energy to zero (lattice and surface);

d. Compute the damage energy according to the following equation where the first term is the beam energy lost to phonons and the second is the target atoms energy due to the phonons (SRIM outputs): $\mathrm{T}_{\mathrm{dam}}=\mathrm{E}^{\mathrm{P}}+\mathrm{E}^{\mathrm{P}}$; and

e. Using the value from (d), calculate the number of displacements according the NRT model using Eq. 4.

These calculations will give the number of vacancies per ion produced $(v)$ due to Kinchin-Pease model and they are estimated by SRIM simulations. With this value, the relationship between fluence (the integral of the accelerator flux over time $(t)$ and the dpa rate is straightforward:

$$
\Psi=\frac{\mathrm{dpa} \cdot t \cdot n}{v}
$$

Which can be inverted for a desired dose or in order to calculate the fluence given a dpa pre-established value. This procedure can be applied to get suitable results for damage profiles in materials caused by ion beams.

\section{THE VIABILITY OF USING LAMFI'S $70 \mathrm{keV}$ IMPLANTER}

In order to investigate the viability to use this technique for nuclear materials research, two experiments were performed using the LAMFI's implanter (Fig. 1) with maximum acceleration voltage of $70 \mathrm{kV}$. This implanter was a donation to the University of São Paulo from the Hahn-Meitner-Institut (HMI) Berlin.

Two beam energies were used in the implantation experiments on aluminum foils: $34 \mathrm{keV}$ of $\mathrm{Ar}^{+1}$ and $68 \mathrm{keV} \mathrm{of} \mathrm{Ar}^{+2}$. The beam current during the irradiation was $10 \mu \mathrm{Acm}^{-2}$ for $34 \mathrm{keV}$ and about $1 \mu \mathrm{Acm}^{-2}$ for $68 \mathrm{keV}$. 


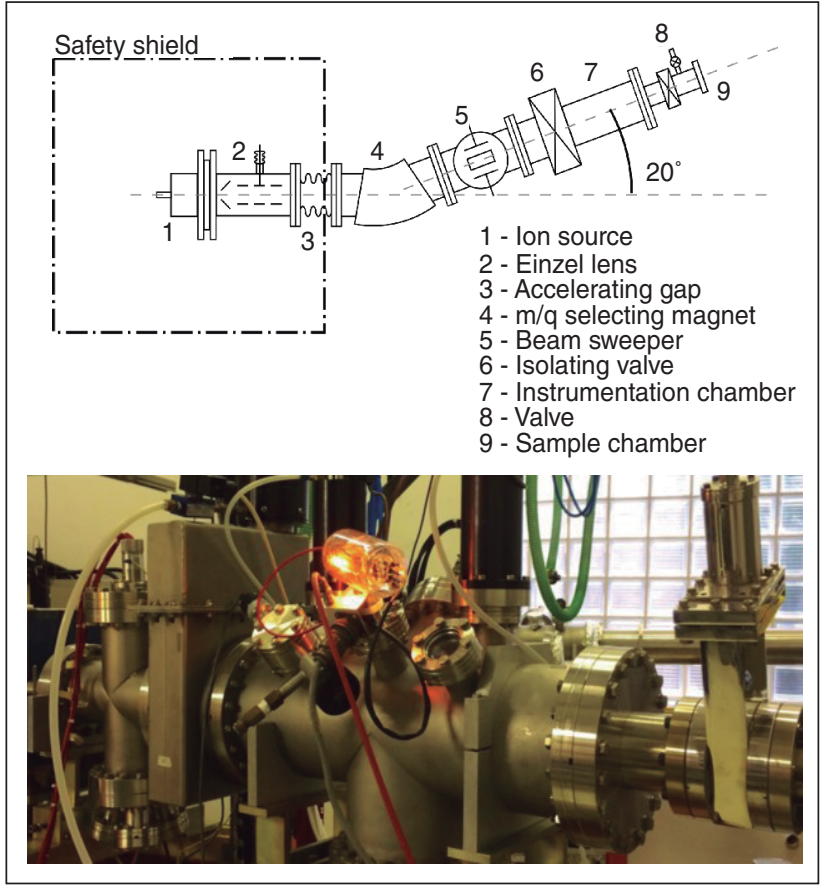

Figure 1: $70 \mathrm{keV}$ ion implanter at the University of São Paulo.

SRIM was used to simulate the damage profile (Fig. 2) which calculates the vacancies per ion per Angstrom and the $\mathrm{Ar}$ implanted profile with the LIO-IFUSP beam configuration. The dpa rates for $34 \mathrm{keV}$ and $68 \mathrm{keV}$ were calculated using the "recipe" described in the last section: the dpa rate is $\mathrm{dpas}^{-1}$ regarding the $34 \mathrm{keV}$ beam and dpas ${ }^{-1}$ to the $68 \mathrm{keV}$. This illustrates, for example, that using the LIO-IFUSP ion beams one can reach 5 dpa on aluminum with just 3 hours of irradiation. Considering that many MTRs in world have a dpa rate (in average) in 10 dpa per year, it is demonstrated the high capability of using LIO-IFUSP ion beams to radiation damage studies. The Fig. 3 is the direct fluence-to-dpa conversion calculated using SRIM simulation outputs for the LILO implanter with the mentioned irradiation conditions.

An experiment using Rutherford-Backscattering (RBS) technique ${ }^{(14,15)}$ at LAMFI was performed in order to determine the amount and depth distribution of Ar implanted in the aluminum foils $(3 \times 3 \times 1 \mathrm{~mm})$. These measurements were taken using a $\mathrm{He}$ beam at $2.2 \mathrm{MeV}$ with a surface barrier detector (20 keV energy resolution) placed at $170^{\circ}$ scattering angle in each irradiation. The argon measured was $51 \mathrm{TFU}$ (thin film unit) for $34 \mathrm{keV}$ and 7 TFU for $68 \mathrm{keV}$ (Figs. 4 and 5).

The Fig. 5 shows a good compatibility with SRIM simulations in the Fig. 1. The implanter is able to accelerate a wide variety of ions, such as $\mathrm{Ar}, \mathrm{He}$ and $\mathrm{H}$ with energies between 5 to $100 \mathrm{keV}$ with powerful computational tools to perform self-consistent ion beam analysis ${ }^{(16,17)}$. In the current scenario, the implanter does not allow any change in the irradiation temperature due to design limitations which has led us to develop of a new sample holder with heating system.

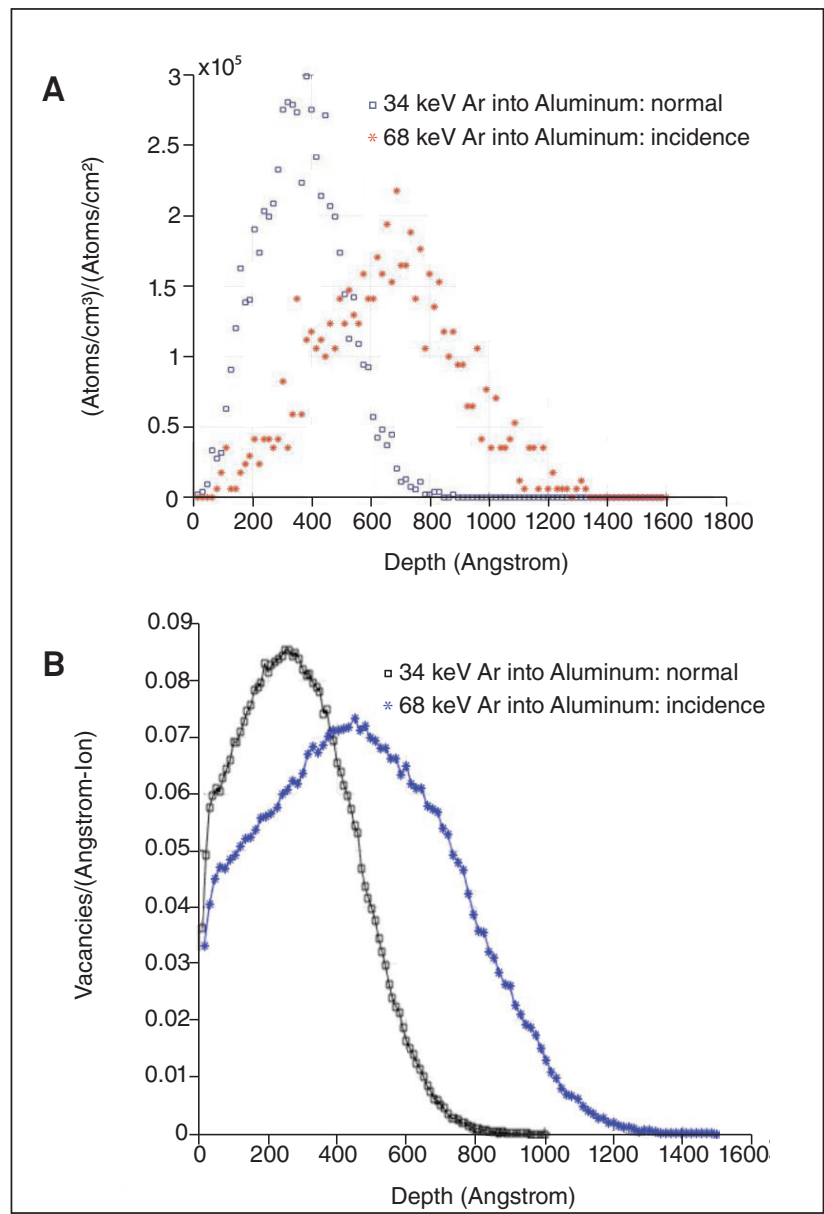

Figure 2: (A) Vacancies estimated by the SRIM2013 with the Kinchin-Pease Quick Damage mode. (B) Ar implanted profile estimated by SRIM2013. Normal incidence: ion beam is normal to the sample's surface.

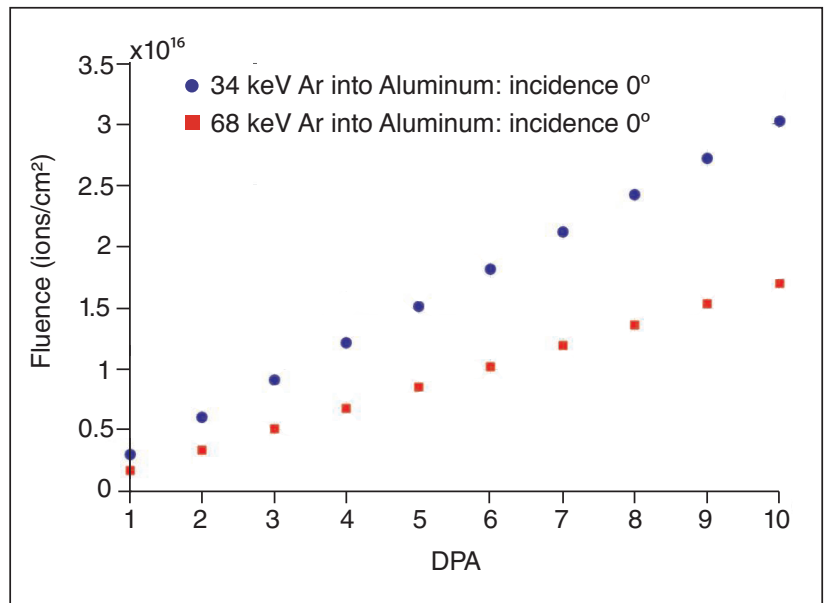

Figure 3: Fluence-to-dpa conversion using SRIM2013 and the procedure suggested by R.E. Stoller et. al. ${ }^{[12]}$.

\section{VACUUM SYSTEM - PUMPING AND MEASUREMENTS: A NEW DESIGN OF A SAMPLE HOLDER WITH HEATING}

The high-vacuum system was designed to reach experimental conditions is based on a turbomolecular pump and a scroll 
pump used as background pump. In this experimental set-up, the operational pressure is around $10^{-7} \mathrm{mbar}\left(10^{-5} \mathrm{~Pa}\right)$. The vacuum chamber and others parts of the system are made with the stainless-steel grade $304 \mathrm{~L}$. Low pressure is required to

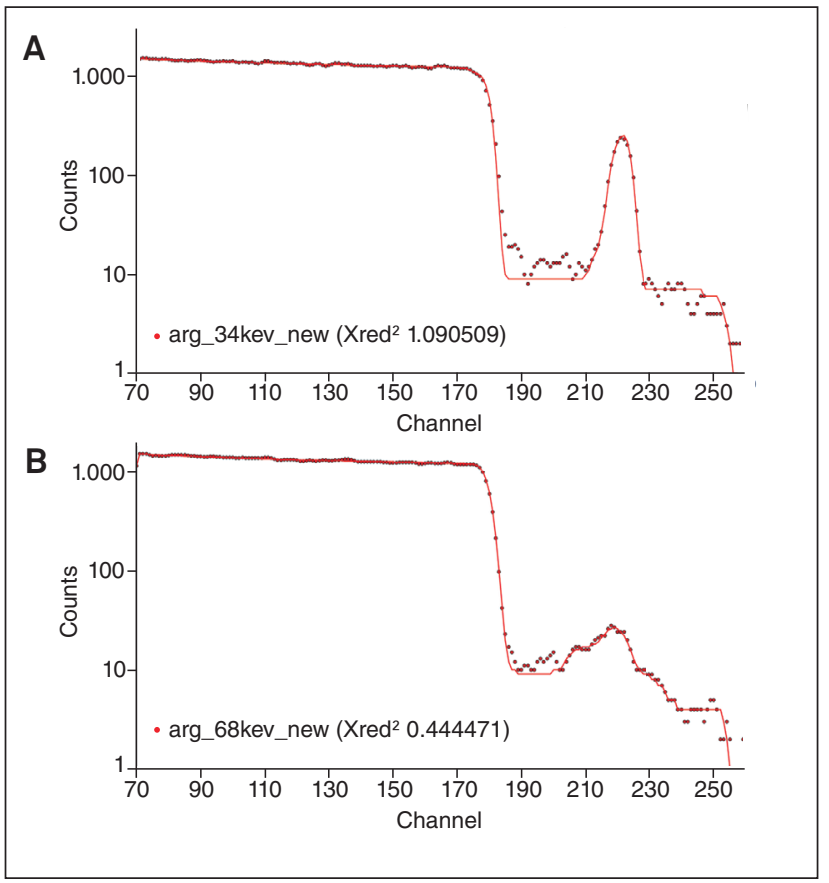

Figure 4: RBS spectra of Ar implanted in aluminum foils $A: 34 \mathrm{keV}$, $\mathrm{B}: 68 \mathrm{keV})$.

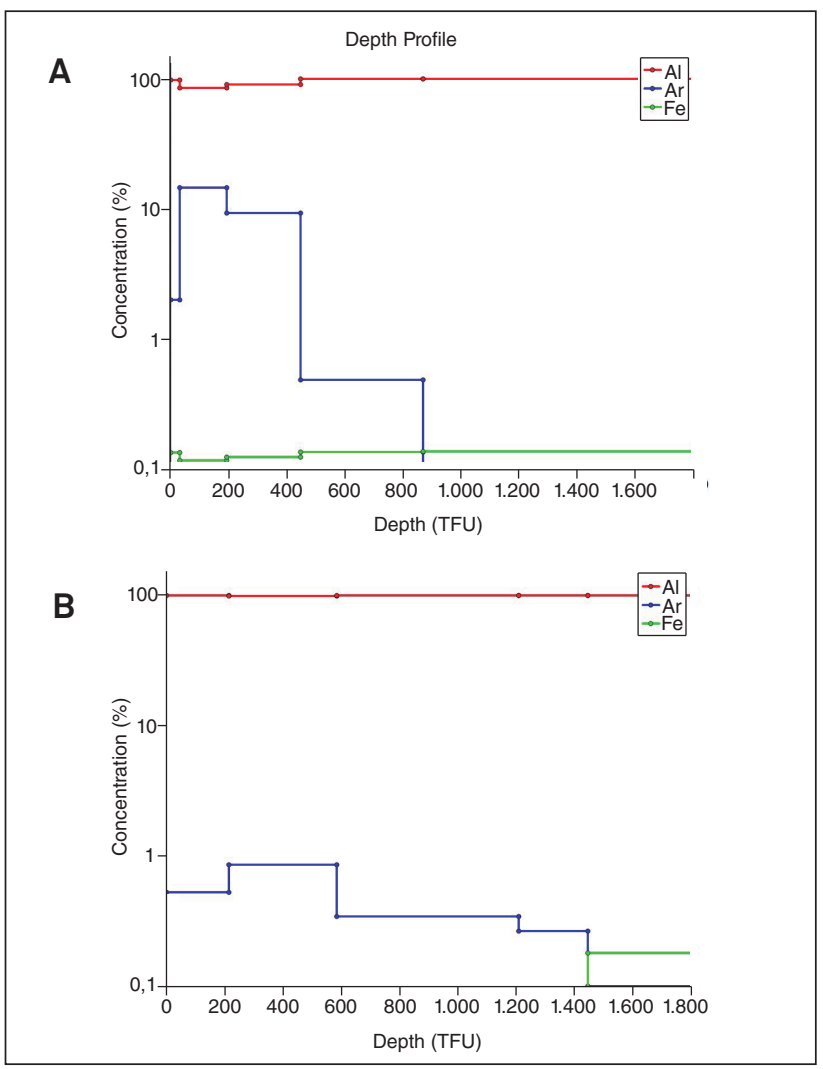

Figure 5: Depth profile of Ar implanted in aluminum foils (A: $34 \mathrm{keV}$, B: 68keV). minimize collisions between the ion beam and residual gas inside the particle accelerator tubes avoiding energy losses and beam dispersion. The Fig. 6 shows the diagram of the vacuum system to be used to this work.

The measurements will be performed with Pirani gauge to low-vacuum and to high-vacuum cold cathode gauge. In order to improve the measurements of the residual gas in vacuum chamber, a residual gas analyzer is needed. For this case the system will be able to acquire the spectrum due to degassing of the walls in the vacuum chamber and also during the ion beam bombardment of the material to be studied $^{(18)}$. During the irradiation, this system allows heating in the sample holder in a range between 25 to $600^{\circ} \mathrm{C}$ by means of resistors which can be replaced in order to achieve higher temperatures.

\section{CONCLUSIONS AND FUTURE WORK}

The argon implantation in the aluminum foils shows high profile compatibility between RBS measurements and simulated results using the SRIM Monte Carlo code. These capabilities could be used in order to support the emulation of the neutron damage using ion beams, as the current understanding in this area lies upon to differentiate the damage profiles caused by ion and neutron spectra ${ }^{(19)}$.

A new design of a vacuum system with heating is also proposed allowing new experimental possibilities, particularly to investigate the role of temperature during irradiation in materials and alloys

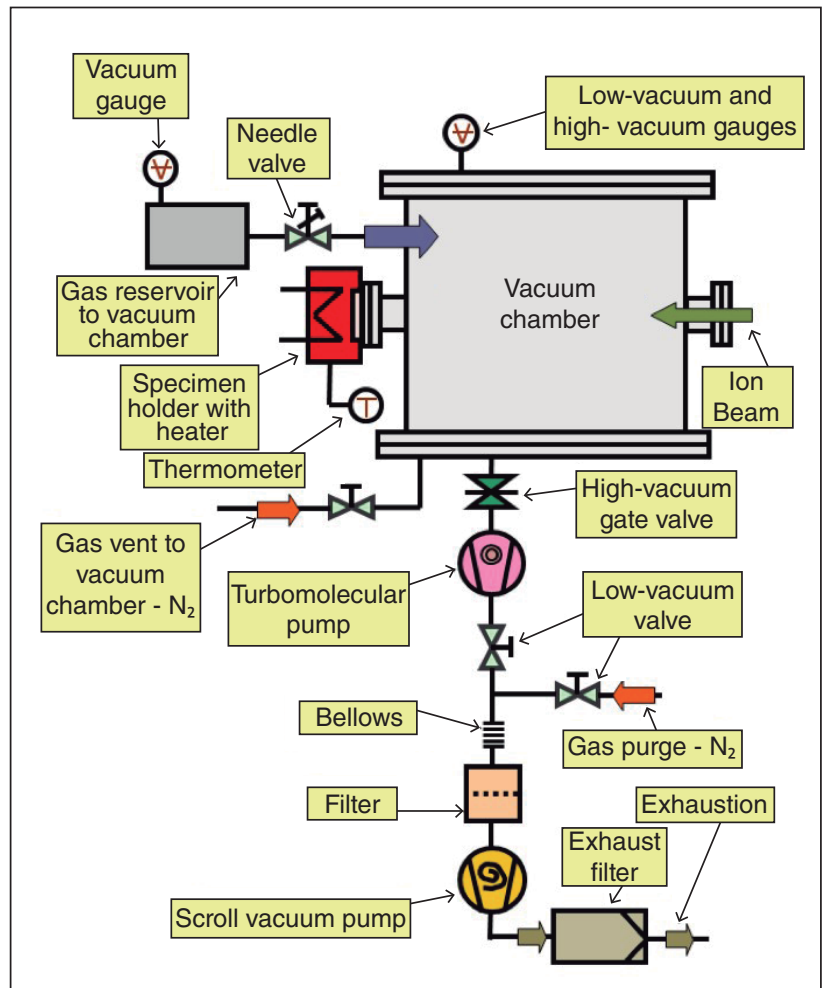

Figure 6: Vacuum system diagram. 
of nuclear industry interests such as stainless steels, zirconium alloys, nickel-based alloys and refractory ceramics.

This work has demonstrated the capabilities of LIO-LAMFI to be inserted in the research field of nuclear materials by means of ion implantation and depth profile measurements. With the recent theoretical developments in the field of radiation damage, it is demonstrated that LIO-LAMFI can be directed to nuclear materials research and be used to study materials and alloys at high levels of doses within a reasonable timeframe.

For future works, it has been considered the use of nanoindentation methods to correlate the irradiated mechanical properties of nanosurfaces with bulk measurements ${ }^{(20)}$, since the implantation profile measured by RBS could indicate the depths to perform nanoindentation as well as to investigate inert gases (Ar, He and $\mathrm{H}$ ) implantation and its effects on the microstructure of materials assessing their mechanical properties.

\section{REFERENCES}

1. ZINKLE. S., WAS, G., Materials challenges in nuclear energy, Acta Materialia, vol. 61, pp. 735-758, feb 2013

2. ZINKLE, S.J., BUSBY, J.T., Structural materials for fission \& fusion energy, Materials Today, vol. 12, no. 11, pp. 12-19, 2009.

3. YVON, P., F. CARRE', F., Structural materials challenges for advanced reactor systems, Journal of Nuclear Materials, vol. 385, no. 2, pp. 217-222, 2009

4. HINKS, J.A., Transmission electron microscopy with in situ ion irradiation, Journal of Materials Research, vol. 30, no. 09, pp. 1214-1221, 2015.

5. WAS, G., JIAO, Z., GETTO, E., SUN, K., MONTERROSA, A. M., MALOY, S., ANDEROGLU, O., SENCER, B., HACKETT, M., Emulation of reactor irradiation damage using ion beams," Scripta Materialia, vol. 88, pp. 33-36, 2014.

6. DONNELLY, S.E., The density and pressure of helium in bubbles in implanted metals: A critical review, Radiation Effects, vol. 90, pp. 1-47, Aug 2006.

7. MADAKSON, P.B., A study of impurity mobility in ion-implanted Al by Rutherford backscattering," Nuclear Instruments and Methods in Physics Research, vol. 218, pp. 537-541, dec 1983.

8. AVERBACK, R., REHN, L., WAGNER, W., OKAMOTO, P., WIEDERSICH, H., In situ Rutherford backscattering analysis of radiation-induced segregation, Nuclear Instruments and Methods in Physics Research, vol. 194, pp. 457-460, mar 1982.
9. HEH, K., B. WEBER, B., Analysis of metallic layer systems by rutherford backscattering spectrometry, Nuclear Instruments and Methods in Physics Research, vol. 199, pp. 387-391, aug 1982.

10. WILLIAMS, J., The application of high-resolution Rutherford backscattering techniques to near-surface analysis, Nuclear Instruments and Methods, vol. 149, pp. 207-217, feb 1978.

11. BRATCHENKO, M.. I., BRYK, V.V., DYULDYA, S.V., KALCHENKO A.S., LAZAREV, N.P., VOYEVODIN, V.N., Comments on DPA calculation methods for ion beam driven simulation irradiations, Problems of Atomic Science and Technology, no. 2, pp. 11-16, 2013

12. STOLLER, R., TOLOCZKO, M., WAS, G., CERTAin, A. DWARAKNATH, S., GARNER, F., On the use of SRIM for computing radiation damage exposure," Nuclear Instruments and Methods in Physics Research Section B: Beam Interactions with Materials and Atoms, vol. 310, pp. 75-80, sep 2013.

13. A. E521, "Standard Practice for Neutron Radiation Damage Simulation by Charged-Particle," Annual Book of ASTM Standards, vol. 12.02, no. Reapproved, pp. 1-21, 2009.

14. TABACNIKS, M. H., Análise de filmes finos por pixe e rbs, Instituto de F'Isica-USP, 1997.

15. TABACNIKS, M. H., The laboratory for material analysis with ion beams: Lamfi-usp," Nuclear Physics, 1998.

16. SILVA, T., RODRIGUES, C., MAYER, M., MORO, M., TRINDADE, G., AGUIRRE, F., ADDED, N., RIZZUTTO, M., TABACNIKS, M. MultiSIMNRA: A computational tool for self-consistent ion beam analysis using SIMNRA, Nuclear Instruments and Methods in Physics Research Section B: Beam Interactions with Materials and Atoms, vol. 371, pp. 86-89, mar 2016.

17. MAYER, M., Improved physics in SIMNRA 7, Nuclear Instruments and Methods in Physics Research Section B: Beam Interactions with Materials and Atoms, vol. 332, pp. 176-180, aug 2014.

18. WIEDEMANN, H., Particle accelerator physics. Springer, 2015

19. WAS, G., BUSBY, J., ALLEN, T., KENIK, E., JENSSON, A., BRUEMMER, S., GAN, J., EDWARDS, A., SCOTT, P., ANDRESON, P., Emulation of neutron irradiation effects with protons: validation of principle, Journal of nuclear materials, vol. 300, no. 2, pp. 198-216, 2002.

20. HOSEMANN, P., SHIN, C., KIENER, D., Small scale mechanical testing of irradiated materials, Journal of Materials Research, vol. 30, pp. 1-15, apr 2015

21. WAS, GARY S. Fundamentals of radiation materials science: metals and alloys. Springer, 2016.

22. THOMPSON, M.W. Defects and radiation damage in metals Cambridge University Press, 1969. 